could do more than hazard a guess at what the legal position would be if (be it for a financial consideration or not) such embryos were to be passed from the clinics in which they had originated to scientific workers, inside or outside industry, wishing to use them for purposes such as organ culture, testing drugs for teratogenesis, studying abnormal cytogenetics, or genetic engineering.

It is vitally important that a small pilot committee be set up immediately to collect, collate, and record information on the fate of every ovum fertilised in vitro in Britain. When parliament comes to debate the report it will obviously be immensely aided if it has available information on the fate of all such ova. During this period before the debate the only constraints imposed on experimentation will have been those suggested by the conscience, good taste, and sense of those working with embryos. The knowledge that parliament was going to debate the report when it had the facts would do much to allay the concern and suspicion of those who as a matter of conscience find experimentation on living human beings repugnant.

D H M Woollam

Ferring,

West Sussex BN12 5ND

' Woollam DHM. Thalidomide disaster considered as an experiment in mammalian teratology. $\mathrm{Br}$ Med
1962 ;ii:236-7.

SIR,-There can be no doctor who does not feel sympathy for the infertile. Each of us can from his own experience produce tragic examples of couples who after endless investigation and many bitter disappointments have to become resigned to a childless marriage. The test tube baby seemed to many to offer hope to those who had been deprived even of the possibility of adoption by the Abortion Act, which since 1967 has prevented the birth of over two million children.

Much water has flowed under the bridge since the birth of Louise Brown. The Warnock report has led many people to ask the question: "Has every couple an absolute right to a child -and a healthy one at that ?" In this consumer age is a child becoming more a status symbol than a product of love? What pressures of society make a woman prepared to undergo the dubious benefits of pregnancy and childbirth for a child that is not her husband's but the outcome of a joyless and anonymous adultery, or not her own child but the offspring of some other woman fertilised by the husband, or worse still, a child created by indiscriminate mating of donor gametes, the product of a sort of ghastly Russian roulette?

Respect for human life has hit an all time low in this country. We already terminate the lives of over 160000 human beings by abortion each year; do we really want to engage in "selection" of embryos with disposal of the "surplus" ? Do we really want to keep embryos frozen for years like miniature Rip van Winkles? Do we really wish to engage in veterinary pursuits like egg donation, surrogate motherhood, and womb leasing ? Womb with a view, rent free ? Do we really think it right that human individuals should be the subject of experimentation whether before or afier that entirely arbitrary 14 day limit ? Have we been hypnotised by the magic word research, so that we do not ask what sort of research and whether the information could be got in some other way? Have we forgotten our embryology, which told us without a doubt that life begins at conception? Can anyone prove otherwise? If not then human rights start at conception too.

Life Doctors-a 50 strong group of doctors working in the Life organisation-would like to contact all doctors who are concerned about the possible implications of the Warnock report. The government has invited views on the report and its recommendations. If we do nothing we have only ourselves to blame for what happens. Has our judgment become so blunted that we are going to accept the report's permissive recommendations without a flicker of conscience? The Warnock report is not yet law, and it need never become so.

M M Heley Organiser, LIFE Doctors Group

Ipswich, Suffolk

\section{Active and passive smoking}

SIR,-Dr J P Vandenbroucke and others (16 June, p 1801) conclude: "Our findings are reassuring to the extent that the possible absolute risk carried by passive smoking is probably small." This assumption may be based on imperfections in their categorisations of smokers and non-smokers. None of the major studies which have shown the much greater detrimental effects of passive smoking use the classification of non-current smoker. ${ }^{1-4}$ Thus the results of the study by Dr Vandenbroucke and others are not comparable with those of the other long term passive smoking studies.

The classification of non-current smoker permits former smokers and smokers of less than one cigarette a day to be considered as non-smokers. This type of categorisation allows former smokers who have quit smoking for a short time (one to five years) due to diseases such as terminal cancer, emphysema, or cardiovascular manifestations to be considered as non-smokers. Such individuals are former smokers and not non-smokers. Similarly, those who smoke less than one cigarette a day should be classified as smokers in a separate category or included in the category of those smoking 10 cigarettes or less a day. Categorisations such as that of Dr Vandenbroucke and others underestimate the exposure to passive smoking and could easily explain the differences between their results and those of other studies.

Another serious problem with the data of $\mathrm{Dr}$ Vandenbroucke and others is that smoking histories were obtained in 1953-4, but the follow up data for the 15 and 25 year analyses were based on mortality data alone. Since individual smoking habits were not checked at the end of the 15 and 25 year periods the smoking habits of these subjects during these time periods were unknown. Many men and women probably quit smoking so the exposure to passive smoking would be much less than that assumed in their data. Thus the effect of long term passive smoking would be masked by the inclusion of the former smokers in the unexposed group.

It is vital for research on long term passive smoking to have as much information as possible on life time smoking habits of those extosing thei spouses, relatives, and friends to passive smoking. The studies which have incomplete or questionable data on smoking histories cannot properly determine the impact of passive smoking since too much overlapping of categories results in misleading data.

The best method to determine the impact of passive smoking on longevity is to compare life time non-smoking women with life time nonexposure to tobacco smoke to life time nonsmoking women with graded levels of tobacco smoke exposure-that is, $10,20,30,40,50$ year intervals of exposure. We would like to suggest that the present study be recalculated using categories which can more accurately be compared with those of other studies on long term passive smoking. We believe that if $\mathrm{Dr}$ Vandenbroucke and others change their categories the detrimental effect of passive smoking will be shown to be much greater than their present report indicates.

G H MILLER

Studies on Smoking,

Edinboro, PA 16412

USA

Charles E Chittenden

Daskais and Walls Inc

Chicago, Illinois 60606

' Hirayama T. Non-smoking wives of heavy smokers have higher risk of lung cancer: a study in Japan. Br Med F 1981;282:183-

'Trichopoulos D, Kalandidi A, Sparros L, MacMahon $B$. Lung cancer and passive smoking. Int $\mathcal{f}$ Cancer $1981 ; 27: 1-4$

Correa P, Pickle LW, Fontham E, Lin Y, Haenszel W. Passive smoking and lung cancer. Lancet 1983;ii:

Miller GH. Cancer, passive smoking and non-
employed and employed wives. Western Med $_{1984}$; 140:632-5.

${ }_{*}^{*}$ Dr Vandenbroucke replies below.-ED, $B M F$.

SIR,-We agree wholeheartedly with the general tenor of the points raised by Dr Miller and $\mathrm{Dr}$ Chittenden. The more precise the characterisation of an exposure the more likely it is that one can pick up even small associations with disease. Our study can be seen as the crudest possible test of an association between an exposure and its health consequences: the exposure is measured once, grouped into coarse categories, and only mortality-many years after the original characterisation-is investigated. Nevertheless, the association between active smoking and premature death in men comes out very strongly - as it does in other studies. Likewise, the much weaker association between smoking and premature death in women, as found by others, is also replicated. We consider this sufficient proof of the validity of this study and its analysis. Therefore we cannot help it if no strong association with passive smoking emerges. Incidentally, one reader informed us that on statistical significance testing there was a significant decrease in mortality among women exposed to a little passive smoking.

In the past we have often been amazed to read how in many epidemiological studies smoking habits of respondents seem to fit so neatly within ideal categories. One explanation is given by Dr Miller and Dr Chittenden. We are counselled to include the person who smokes less than one cigarette a day in the category of smokers (0-10 cigarettes/day) and to do our analysis of passive smoking over again. This would include the husband who on close questioning admits to a single small cigar on New Year's Eve and possibly a cigarette or two at his last birthday party. We do not think that the suggestion that we should classify this person's non-smoking wife as exposed to passive smoking (0-10 cigarettes/ day) should be taken seriously.

In general we are constrained by the limitations of our data, but we would like to recall in this respect the words of R R Monson: "Few data sets are worthless and few convey absolute truth."

\section{$\mathrm{J}$ P VANDENBROUCKE}

Department of Epidemiology,

Erasmus University Rotterdam,

3000 DR Rotterdam

Monson RR. Occupational epidemiology. Boca Raton,
Florida: CRC-Press, 1980:31. 